\title{
Effects of Nitrogen Fertilizer on Grain Yield and Fragrant Contents in two Thai Rice Varieties
}

\author{
${ }^{1}$ Ayut Kongpun and ${ }^{2,3 *}$ Chanakan Thebault Prom-u-Thai \\ ${ }^{1}$ Faculty of Agricultural Technology, Kalasin University, Kalasin 46000, Thailand \\ ${ }^{2}$ Department of Plant and Soil Sciences, Faculty of Agriculture, Chiang Mai University, Chiang Mai 50200, Thailand \\ ${ }^{3}$ Lanna Rice Research Center, Chiang Mai University, Chiang Mai 50200, Thailand
}

\author{
Article history \\ Received: 04-05-2021 \\ Revised: 21-06-2021 \\ Accepted: 30-06-2021 \\ Corresponding Author: \\ Chanakan Thebault Prom-u- \\ Thai \\ Faculty of Agricultural \\ Technology, Kalasin \\ University, Kalasin 46000, \\ Thailand \\ Email: chanakan15@hotmail.com
}

\begin{abstract}
Nitrogen $(\mathrm{N})$ is commonly applied in rice crop production for improving grain quality and productivity. This experiment aimed to evaluate how applying $\mathrm{N}$ fertilizer affects the concentration of 2-Acetyl-1-Pyrroline (2AP), the major fragrant compound in rice grains, between two selected rice varieties with high yield potential and fragrant scent, Pathum Thani 1 (PTT1) and $\mathrm{RD} 22$. Rice plants were grown in pot conditions and $\mathrm{N}$ fertilizer was applied in three rates at 2.44, 3.82 and $5.66 \mathrm{~g} \mathrm{~N} /$ pot designated as N1, N2 and N3, respectively. Rice samples were harvested at maturity and evaluated for grain yield, grain $\mathrm{N}$ and 2AP concentration. The results revealed that grain yield and concentration of $\mathrm{N}$ and $2 \mathrm{AP}$ were affected by $\mathrm{N}$ rates differently between the varieties; RD22 had higher grain yield and the concentrations of $\mathrm{N}$ and 2AP than PTT1 with all N rates. Grain N concentration in both varieties increased when increasing $\mathrm{N}$ rates. There was highly positive correlation between grain $\mathrm{N}$ and grain $2 \mathrm{AP}$ concentration among the $\mathrm{N}$ rates and varieties. We conclude that applying $\mathrm{N}$ in rice cultivation not only improves productivity but also enhances the quality of rice grains by improving the concentrations of $\mathrm{N}$ and $2 \mathrm{AP}$, the magnitude of the effect depending on the rice variety.
\end{abstract}

Keywords: Fragrant Rice, Aroma Rice, Nitrogen Fertilizer, 2-Acetyl-1-

Pyrroline (2AP)

\section{Introduction}

Fragrant rice is a major type of rice that has a high value in the global rice markets (Roy et al., 2020). The price of fragrant milled rice, e.g., Hom mali (jasmine rice), a popular Thai fragrant rice, is about double that of the non-fragrant rice (TREA, 2021). Thai fragrant rice is famous worldwide not only for its premium quality and soft texture of cooked grains but also for the unique scent (Giraud, 2013). The 2-Acetyl-1-Pyrroline (2AP) in rice grains is a key compound determining the scent and is strongly correlated with the fragrance (Nadaf et al., 2014). The 2AP content in grains is under tight genetic control but can be affected by cultivation management (Roy et al., 2020). There are many aromatic rice varieties in the world that have been well recognized by consumers, e.g., Basmati from India, Jasmine rice from Thailand, Bahra from Afghanistan and Della, Texamati and Kasmati from the United States (Singh et al., 2000). In Thailand, the prevalence of fragrant varieties can be found in both photosensitive (e.g., Khao Dawk Mali 105 and RD6) and non-photosensitive (e.g., Pathum Thani 1 and RD
22) rice, where the fragrant type is more dominant in the photosensitive varieties compared with the nonphotosensitive varieties. However, due to the greater fragrance but limited potential for productivity in the photosensitive varieties, new varieties of fragrant rice with non-photosensitive characteristics have been bred according to the demands of farmers and consumers (Vanavichit et al., 2018). Although the price and popularity of the non-photosensitive fragrant rice varieties are lower than those of the photosensitive varieties, the cultivation and consumption are continuing to increase due to the better agronomic characteristics and yield potential (Boontakham et al., 2019). The Thailand Rice Department suggests that for $\mathrm{N}$ fertilizer application in non-photosensitive fragrant rice varieties such as Pathum Thani 1 and RD 22, the response to fertilizer application should be double that associated with the same application rate among the photosensitive varieties such as Khao Dawk Mali 105 and RD15, but the exact rates should be based on soil property testing or "tailor-made fertilizer" techniques (RD, 2016). 
Grain 2AP content depends on both the rice variety and environmental factors during cultivation that impact 2AP concentration. Kongpun et al. (2020) reported that growing rice variety Khao Dawk Mali 105 in a slightly saline soil enhanced 2AP accumulation in rice grains. Additionally, growing rice crops under drought stress conditions during the milky ripening stage was reported to enhance grain 2AP content (Yoshihashi et al., 2002). Nitrogen is a common fertilizer applied in rice crop cultivation together with other nutrients, mainly phosphorus and potassium, for boosting productivity and grain quality. Applying $\mathrm{N}$ fertilizer at booting stage has been found to improve grain aroma content, but overapplication of $\mathrm{N}$ could decrease the content (Mo et al., 2018). The effect of $\mathrm{N}$ fertilizer on the aroma has been reported in several studies, but there is limited information concerning how applying $\mathrm{N}$ affects the aroma. We hypothesized that applying $\mathrm{N}$ may affect grain $\mathrm{N}$ accumulation and that this may be associated with the grain aroma. This study set out to evaluate the effects of $\mathrm{N}$ application rates on grain yield and the contents of $\mathrm{N}$ and 2AP in non-photosensitive fragrant rice varieties. The results from this study should be useful for improving the fragrant rice varieties with high $2 \mathrm{AP}$ content by adjusting $\mathrm{N}$ fertilizer management during cultivation.

\section{Materials and Methods}

\section{Experimental Design and Plant Culture}

A pot experiment was conducted at the Department of Plant Production Technology, Kalasin University, Kalasin Province, Thailand during the dry season from December 2018 to April 2019. The experiment was arranged in a factorial design with two factors and three independent replications. The first factor was the rice varieties of Pathum Thani 1 (PTT1) and RD22, highyield varieties with photoperiod insensitivity. The second factor was three $\mathrm{N}$ fertilizer rates of 2.44, 3.82 and $5.66 \mathrm{~g} \mathrm{~N} /$ pot designated as $\mathrm{N} 1, \mathrm{~N} 2$ and $\mathrm{N} 3$, respectively, where $\mathrm{N} 2$ represents the common rate for $\mathrm{N}$ requirement among the varieties (Ali et al., 2020). Rice seeds were directly sown in $10 \mathrm{~L}$ plastic pots containing $13 \mathrm{~kg}$ soil (4.4\% moisture content). Soil samples were taken for analysis profiling before being used in the experiment. Eight seeds were sown in each pot and the seedlings were thinned to two plants per pot at 11 days after sowing. The water level in each pot was maintained at $2-5 \mathrm{~cm}$ above the soil surface until harvesting. Nitrogen fertilizer was applied equally by splitting into four applications at 16, 48, 77 and 104 day after sowing; these corresponded to the seedling, floral initiation, booting and grain filling stages, respectively. The phosphorus (1.39 g $\mathrm{P} /$ pot) and potassium (2.63 $\mathrm{g} \mathrm{K} / \mathrm{pot})$ were applied four times as for the $\mathrm{N}$ application. At maturity, grain yield and yield components were evaluated and seeds samples were kept in a cold room at $18^{\circ} \mathrm{C}$ before being subjected to chemical analysis.
Table 1: The fertility profile of soil used in this experiment

\begin{tabular}{lr}
\hline Soil properties & \\
\hline Organic matter (OM) (\%) & 0.180 \\
Total N (\%) & 0.010 \\
Extractable P (Bray II) (mg/kg) & 1.330 \\
Exchangeable K (mg/kg) & 12.000 \\
Electrical conductivity (1:5, soil: water) $(\mathrm{mS} / \mathrm{cm})$ & 0.095 \\
$\mathrm{pH}$ & 5.200 \\
\hline
\end{tabular}

\section{Soil Properties}

The soil in this experiment was a sandy loam (68.5\% Sand, $16.5 \%$ Silt and $15.0 \%$ Clay); the properties are given in Table 1. The soil $\mathrm{pH}$ was slightly acidic with low organic matter and N, P, K concentrations, with no salinity stress on rice growth based on the EC (Wolf, 1999).

\section{Chemical Analysis}

About $10 \mathrm{~g}$ of each paddy rice sample was de-husked to yield brown rice grain. A key aroma compound, 2acetyl-1-pyrroline (2AP), was evaluated based on the fresh extract of uncooked brown rice via capillary gas chromatography-mass spectrometry using the method of Mahatheeranont (2001). Grain N concentration in brown rice was evaluated by the Kjeldahl method.

\section{Statistical Analysis}

Data were analyzed using two-way analysis of variance. The differences among treatment means were compared using least significant difference at $P<0.05$. Associations between datasets were determined using correlation analysis.

\section{Results and Discussion}

\section{Yield and Yield Components}

Grain yield was affected by $\mathrm{N}$ application rates differently between the two fragrant varieties (Fig. 1). The variety RD22 had higher grain yield than PTT1 in all applied N rates. In PTT1, grain yield increased from 35.4 to $55.8 \mathrm{~g} /$ pot when increasing $\mathrm{N}$ rates from $\mathrm{N} 1$ to $\mathrm{N} 2$, but yield was decreased to $34.9 \mathrm{~g} /$ pot when applied with N3. In contrast, grain yield of RD22 was increased from 62.5 to $93.2 \mathrm{~g} /$ pot when increasing the $\mathrm{N}$ rate from $\mathrm{N} 1$ to $\mathrm{N} 2$, while increasing $\mathrm{N}$ rate from $\mathrm{N} 2$ to $\mathrm{N} 3$ had no effect on grain yield. Nitrogen fertilizer is commonly used to increase crop yield (Liu et al., 2018; Duncan et al., 2018) due to it being an integral constituent of proteins, nucleic acids, chlorophyll, co-enzymes, phytohormones and secondary metabolites (Marschner et al., 2011). The efficacy of $\mathrm{N}$ fertilizer on yield potential varies according to rice variety and many other factors; over application of 
the fertilizer can be toxic and reduce yield in rice crops (Jaksomsak et al., 2017; Duncan et al., 2018).

Yield components are major parameters that reflect on the final grain yield in rice crops and these vary among rice varieties. It is well established that the yield components of rice varieties with high yield potential are much more responsive to $\mathrm{N}$ fertilizer than varieties with low yield potential (Ladha et al., 1998). This study found that the yield components were affected by $\mathrm{N}$ rates differently between the two varieties (Table 2). The number of panicles per plant of PTT1 (24.7) was higher than in RD22 (17.7). Increasing N rates from N1 to $\mathrm{N} 2$ and N3 increased panicle number from 15.1 to 21.9 and 26.5 per plant, respectively. Number of grains per panicle of PTT1 was not affected by increasing N rates from $\mathrm{N} 1$ to $\mathrm{N} 2$ (46.0 and 49.2 grain/panicle, respectively) but was depressed to 23.4 grains/panicle by applying the higher $\mathrm{N}$ rate (N3). In RD22, increasing $\mathrm{N}$ rates from $\mathrm{N} 1$ to $\mathrm{N} 2$ increased the number of grains per panicle from 91.7 to 101.9 , but increasing $\mathrm{N}$ rates to N3 decreased it to 97.7 grains per panicle. The thousand grain weight of PTT1 was not affected by N rate, but in RD22 increasing the $\mathrm{N}$ rate from N1 to N2 and N3 decreased the thousand grain weight from 25.0 to 22.3 and $22.2 \mathrm{~g}$, respectively.

\section{Grain $N$ and $2 A P$ Concentration}

Applying $\mathrm{N}$ affected grain $\mathrm{N}$ concentration differently between the varieties (Fig. 2A). Grain N concentration of PTT1 was the lowest when applied at the rate N1 $(1.42 \%)$ and was increased to 1.53 and $1.55 \%$ when applied with $\mathrm{N} 2$ and $\mathrm{N} 3$, respectively. In RD22, application with $\mathrm{N} 1$ resulted in grain $\mathrm{N}$ at $1.58 \%$. Increasing the $\mathrm{N}$ rate to $\mathrm{N} 2$ had no effect on grain $\mathrm{N}$ $(1.65 \%)$, while grain $\mathrm{N}$ was increased to $1.81 \%$ when applied with N3 (Fig. 2A). The results were in accordance with a previous study reporting that applying $\mathrm{N}$ at $120 \mathrm{~kg}$ ha-1 to a rice crop resulted in higher grain $\mathrm{N}$ concentrations, but the increase percentage depended on $\mathrm{N}$ rate and rice variety (Jaksomsak et al., 2017).

Grain 2AP concentration affected by $\mathrm{N}$ rates differently between the varieties (Fig. 2B). In PTT1, increasing $\mathrm{N}$ rate from $\mathrm{N} 1$ to $\mathrm{N} 2$ increased grain $2 \mathrm{AP}$ concentration from 0.88 to $1.35 \mathrm{mg} / \mathrm{kg}$, but the concentration was not affected from N2 to N3 (1.32 $\mathrm{mg} / \mathrm{kg}$ ). In RD22, increasing $\mathrm{N}$ rate from $\mathrm{N} 1$ to $\mathrm{N} 2$ decreased grain 2AP from 3.23 to $2.89 \mathrm{mg} / \mathrm{kg}$, but applying N2 increased grain 2AP to $3.55 \mathrm{mg} / \mathrm{kg}$.

\section{Relationship between Grain Yield, Grain $N$ and Grain 2AP Concentration}

There were significant positive linear relationships between grain yield and grain nitrogen concentration $(\mathrm{r}=$ $0.83, \mathrm{P}<0.01$ ) (Fig. $3 \mathrm{~A}$ ), grain yield and grain $2 \mathrm{AP}$ concentration $(r=0.81, P<0.01)$ (Fig. $3 \mathrm{~B})$ and grain $\mathrm{N}$ and grain $2 \mathrm{AP}$ concentration $(\mathrm{r}=0.82, \mathrm{P}<0.01)$ (Fig. $3 \mathrm{C})$.

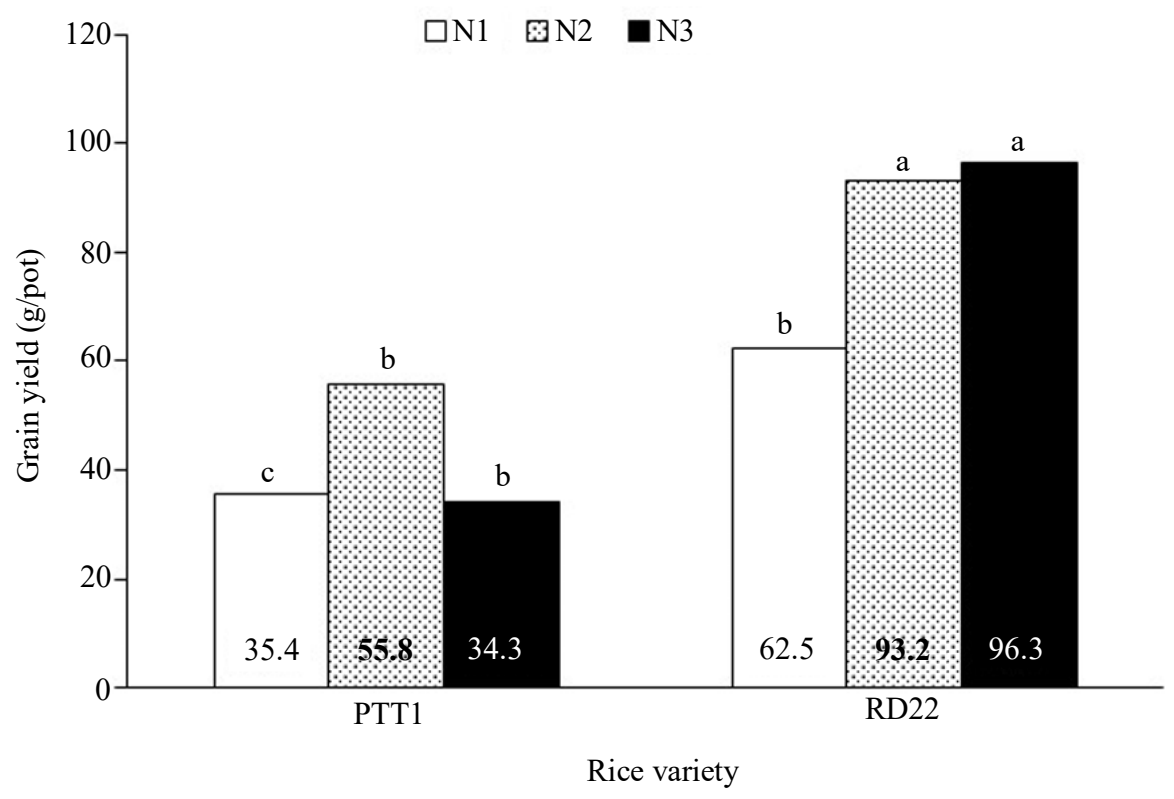

Fig. 1: Effects of $\mathrm{N}$ rates on grain yield in Pathum Thani 1 (PTT1) and RD22 rice varieties. The values are means of three replications. The different lowercase letters indicate significant differences by LSD 0.05 


\section{$\square \mathrm{N} 1 \mathrm{R} \mathrm{N} 2 \square \mathrm{N} 3$}

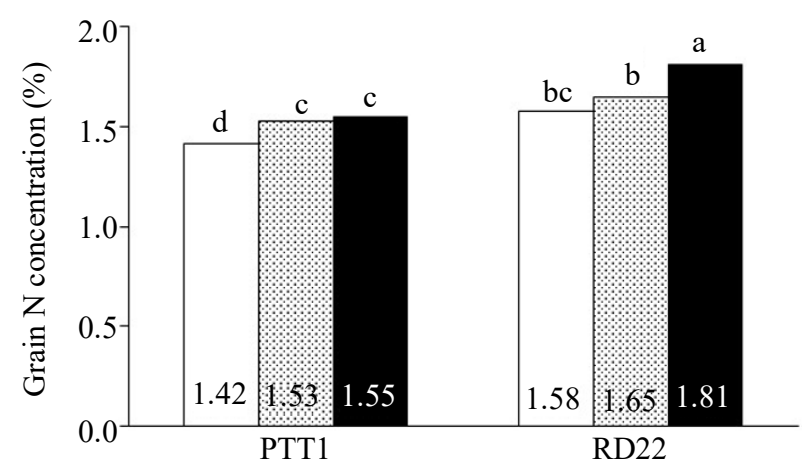

Rice variety

(a)

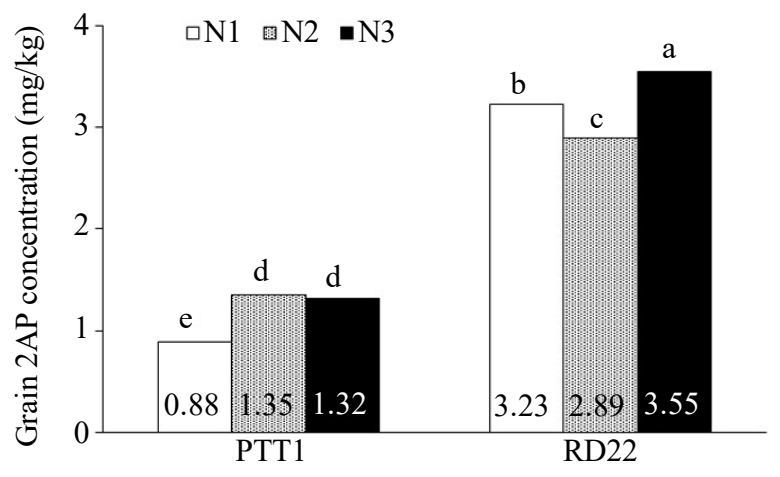

Rice variety

(b)

Fig. 2: Effects of $\mathrm{N}$ rates on grain $\mathrm{N}$ concentration (A) and grain 2AP concentration (B) of Pathum Thani 1 (PTT1) and RD22 rice varieties. The values are means of three replications. The different lowercase letters indicate significant differences by $\mathrm{LSD}_{0.05}$

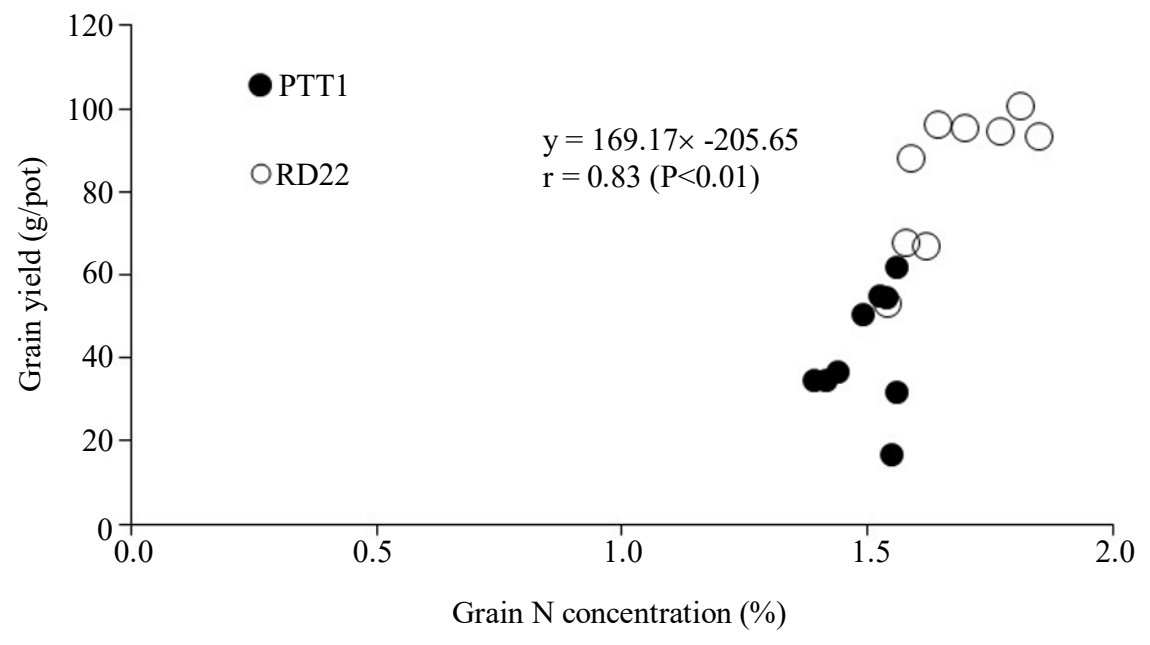

(A)

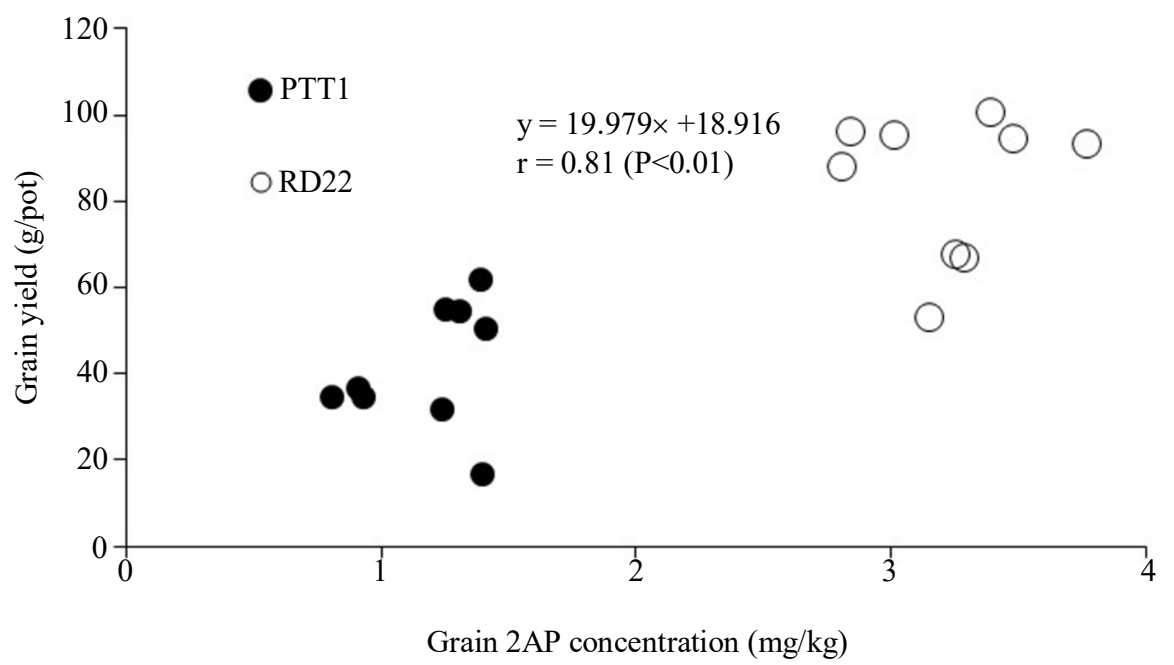

(B) 


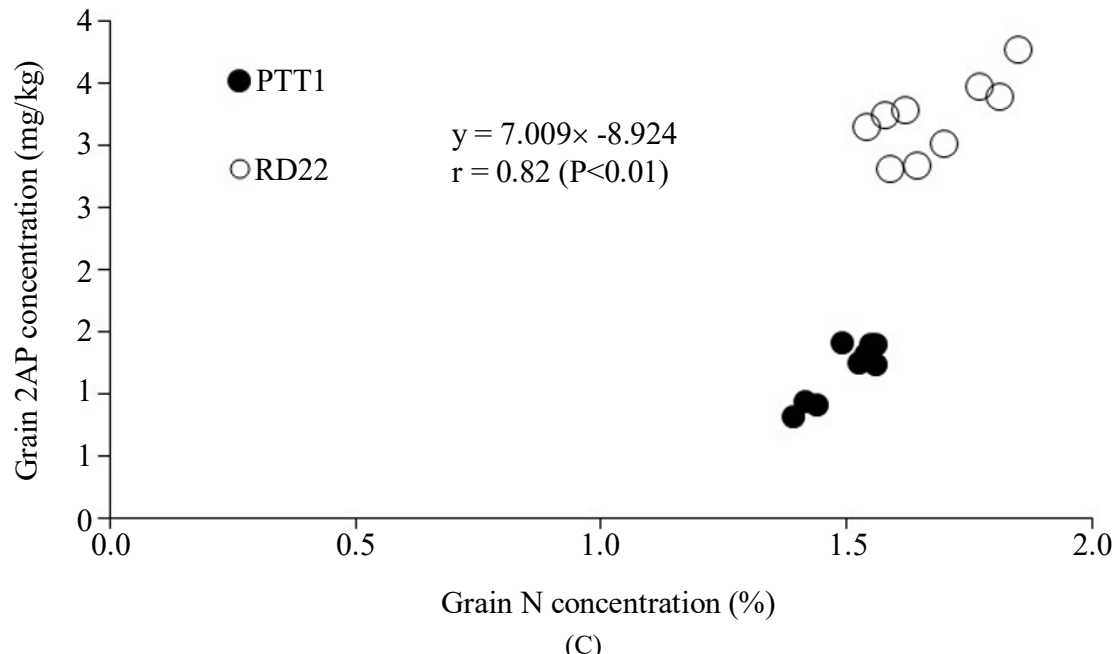

Fig. 3: Relationship between grain yield and grain $\mathrm{N}$ concentration (A), grain yield and grain $2 \mathrm{AP}$ concentration (B) and grain $\mathrm{N}$ and grain $2 \mathrm{AP}$ concentration $(\mathrm{C}), \mathrm{r}=$ correlation coefficient (highly significant difference at $P<0.01$ )

Table 2: Number of panicles per plant and number of filled grains per panicle of two rice varieties grown under different nitrogen fertilizer rates

\begin{tabular}{|c|c|c|c|c|}
\hline \multirow[b]{2}{*}{ Variety } & \multicolumn{3}{|c|}{ Nitrogen rate } & \multirow[b]{2}{*}{ mean } \\
\hline & N1 & $\mathrm{N} 2$ & $\mathrm{~N} 3$ & \\
\hline \multicolumn{5}{|c|}{ Number of panicles per plant } \\
\hline PTT 1 & 17.5 & 25.7 & 30.9 & $24.7 \mathrm{a}$ \\
\hline RD22 & 12.7 & 18.2 & 22.3 & $17.7 b$ \\
\hline Mean & $15.1 \mathrm{C}$ & $21.9 \mathrm{~B}$ & $26.6 \mathrm{~A}$ & \\
\hline F-test & $\mathrm{V}^{* *}$ & $\mathrm{~N}^{* *}$ & $\mathrm{~V} \times \mathrm{N}^{\mathrm{NS}}$ & \\
\hline \multicolumn{5}{|c|}{ Number of filled grains per panicle } \\
\hline PTT 1 & $46.0 \mathrm{c}$ & $49.2 \mathrm{c}$ & $23.4 \mathrm{~d}$ & 39.5 \\
\hline RD22 & $97.1 \mathrm{~b}$ & $101.9 \mathrm{a}$ & $97.7 \mathrm{~b}$ & 98.9 \\
\hline Mean & 71.8 & 75.5 & 60.5 & \\
\hline F-test & $\mathrm{V}^{* *}$ & $\mathrm{~N}^{* *}$ & $\mathrm{~V} \times \mathrm{N}^{*}$ & \\
\hline \multicolumn{5}{|c|}{1,000 grain weight $(\mathrm{g})$} \\
\hline PTT 1 & $19.4 \mathrm{~d}$ & $20.8 \mathrm{~cd}$ & $19.3 \mathrm{~d}$ & 19.8 \\
\hline RD22 & $25.0 \mathrm{a}$ & $23.3 \mathrm{~b}$ & $22.2 \mathrm{bc}$ & 35.2 \\
\hline Mean & 22.2 & 22.0 & 20.7 & \\
\hline F-test & $\mathrm{V}^{*}$ & $\mathrm{~N} * *$ & $\mathrm{~V} \times \mathrm{N}^{*}$ & \\
\hline
\end{tabular}

$\mathrm{N}=$ nitrogen rate, $\mathrm{V}=$ rice variety, $\mathrm{N} \times \mathrm{V}=$ interaction effects between nitrogen rate and rice variety, $*=$ significant $(P<0.05), * *=$ highly significant $(P<0.01)$, ns $=$ non-significant $(P>0.05)$. Means in the same column followed by different letters indicate significant differences at $P<0.05$

This experiment has established that applying $\mathrm{N}$ fertilizer enhanced grain 2AP accumulation in the high yield and non-photosensitive fragrant rice varieties. This may be the result of increasing grain $\mathrm{N}$ concentration due to the strong positive correlation between grain $\mathrm{N}$ and 2AP concentration found in this study. It has been documented that proline compounds and amino acids having $\mathrm{N}$ as the main component are major precursors in the pathway of 2AP synthesis (Nadaf et al., 2014). Several studies have confirmed that applying $\mathrm{N}$ fertilizer to rice crops during cultivation increased the proline compounds and 2AP concentrations in rice grains, but most such conclusions were based on the relationship between $\mathrm{N}$ application rates and grain 2AP concentration (Mo et al., 2018; Yang et al., 2012). Additionally, the effect of $\mathrm{N}$ application on grain 2AP content depends on growing conditions of the rice crop, as it has been reported that applying nitrogen to lead $(\mathrm{Pb})$ contaminated soil increased grain yield and 2AP content differently in three fragrant rice varieties (Huoyi et al., 2020). A recent study has reported that applying $\mathrm{N}$ fertilizer with less irrigation water at tillering stage not only increased head rice yield but also enhanced 2AP content in rice grains (Li et al., 2021). Thus, applying $\mathrm{N}$ fertilizer under varied growing conditions may have different effects on the available $\mathrm{N}$ concentration in the soil for the plant's absorption and 
uptake, which may consequently impact grain 2AP concentration. In fact, $\mathrm{N}$ application rates and/or soil $\mathrm{N}$ concentration are not always associated with the total $\mathrm{N}$ uptake in rice plants and grain accumulation, but rather are indicated by $\mathrm{N}$ concentrations in specific plant tissues (Reuter and Robinson, 1997). Additionally, this study has shown that the variety PTT1 accumulated less grain 2AP than in RD22, although both rice varieties were applied with the same rates of $\mathrm{N}$, indicating that the effect of $\mathrm{N}$ rates on grain 2AP concentration is highly dependent on the rice variety. Therefore, for high grain fragrance, the appropriate rate of $\mathrm{N}$ fertilizer application should be carefully considered when dealing with different rice varieties and cultivation strategies. A highly positive correlation between grain $\mathrm{N}$ and grain $2 \mathrm{AP}$ concentration was found among $\mathrm{N}$ rates and rice varieties, indicating that grain $\mathrm{N}$ concentration is a promising indicator for determining grain 2AP concentration. A recent study found that applying Molybdenum (Mo) fertilizer enhanced the utilization and assimilation of $\mathrm{N}$ in rice plants and consequently improved yield and 2AP concentration in rice grains in two fragrant varieties grown under Cadmium (Cd) stress (Imran et al., 2021). This confirmed that the factors enhancing $\mathrm{N}$ absorption, transport and accumulation in plant tissues may be the key parameters for increasing grain 2AP concentration among fragrant rice varieties. However, similar experiments with more rates of $\mathrm{N}$ application and fragrant rice varieties are required for confirmation of the relationship between grain $\mathrm{N}$ and $2 \mathrm{AP}$ concentration in rice crops. The results of this study will be useful for determining the proper application of $\mathrm{N}$ fertilizer for improving grain yield and quality in fragrant rice.

\section{Conclusion}

Grain $\mathrm{N}$ concentration is a promising indicator for determining grain 2AP accumulation in fragrant rice varieties and $\mathrm{N}$ concentration can be improved by applying the appropriate rate of $\mathrm{N}$ fertilizer. The magnitude of the increase in grain 2AP concentration by $\mathrm{N}$ application in fragrant rice depends on the rice variety and growing conditions. We conclude that increasing $\mathrm{N}$ application rate in rice cultivation would help to improve grain yield and grain $\mathrm{N}$ concentration, thereby increasing the 2AP concentration in rice grains. This study has further indicated that the fragrant rice variety RD22 showed higher efficiency of $\mathrm{N}$ localization and fragrance quality in the grains than PTT 1.

\section{Acknowledgments}

We would like to thank Rice Department, Ministry of Agriculture and Cooperatives, Thailand for providing rice seeds in this experiment.

\section{Funding Information}

This study was partially supported by Research Center for Development of Local Lanna Rice and Rice Products, Chiang Mai University, Thailand.

\section{Author's Contributions}

Ayut Kongpun: Designed the experiment, conducted the research and contributed to results analysis and drafting the manuscript.

Chanakan Thebault Prom-u-Thai: Analyzed grain chemical properties, edited the manuscript and submitted the manuscript.

\section{Ethics}

This article is original and contains unpublished material. The corresponding author confirms that the coauthor has read and approved the manuscript and that there are no ethical issues involved.

\section{References}

Ali, I., Ullah, S., He, L., Zhao, Q., Iqbal, A., Wei, S., ... \& Jiang, L. (2020). Combined application of biochar and nitrogen fertilizer improves rice yield, microbial activity and $\mathrm{N}$-metabolism in a pot experiment. PeerJ, 8, e10311. https://peerj.com/articles/10311/

Boontakham, P., Sookwong, P., Jongkaewwattana, S., Wangtueai, S., \& Mahatheeranont, S. (2019). Comparison of grain yield and 2-acetyl-1-pyrroline (2AP) content in leaves and grain of two Thai fragrant rice cultivars cultivated at greenhouse and open-air conditions. Australian Journal of Crop Science, 13(1), 159-169. https://search.informit.org/doi/abs/10.3316/informit. 337746941842720

Duncan, E. G., O'Sullivan, C. A., Roper, M. M., Palta, J., Whisson, K., \& Peoples, M. B. (2018). Yield and nitrogen use efficiency of wheat increased with root length and biomass due to nitrogen, phosphorus and potassium interactions. Journal of Plant Nutrition and Soil Science, 181(3), 364-373. https://onlinelibrary.wiley.com/doi/abs/10.1002/jp $\ln .201700376$

Giraud, G. (2013). The world market of fragrant rice, main issues and perspectives. International Food and Agribusiness Management Review, 16(10302016-82817), 1-20. https://ageconsearch.umn.edu/record/148577/

Imran, M., Hussain, S., Rana, M. S., Saleem, M. H., Rasul, F., Ali, K. H., .. \& Tang, X. (2021). Molybdenum improves 2-acetyl-1-pyrroline, grain quality traits and yield attributes in fragrant rice through efficient nitrogen assimilation under cadmium toxicity. Ecotoxicology and Environmental Safety, 211, 111911. https://doi.org/10.1016/j.ecoenv.2021.111911 
Jaksomsak, P., \& Rerkasem, B. (2017). Responses of grain zinc and nitrogen concentration to nitrogen fertilizer application in rice varieties with highyielding low-grain zinc and low-yielding high grain zinc concentration. Plant and Soil, 411(1-2), 101109. https://doi.org/10.1007/s11104-016-3056-1.

Kongpun, A., Jaisiri, P., \& Rerkasem, B. (2020). Impact of soil salinity on grain yield and aromatic compound in Thai Hom Mali rice cv. Khao Dawk Mali 105. Agriculture and Natural Resources, 54(1), 74-78. https://li01.tcithaijo.org/index.php/anres/article/view/240264

Ladha, J. K., Kirk, G. J. D., Bennett, J., Peng, S., Reddy, C. K., Reddy, P. M., \& Singh, U. (1998). Opportunities for increased nitrogen-use efficiency from improved lowland rice germplasm. Field Crops Research, 56(1-2), 41-71. https://doi.org/10.1016/S0378-4290(97)00123-8.

Li, Y., Mo, Z., Li, Y., Nie, J., Kong, L., Ashraf, U., ... \& Tang, X. (2021). Additional Nitrogen Application Under Different Water Regimes at Tillering Stage Enhanced Rice Yield and 2-Acetyl-1-Pyrroline (2AP) Content in Fragrant Rice. Journal of Plant Growth Regulation, 1-11. https://link.springer.com/article/10.1007/s00344021-10351-0

Liu, H., Zhao, P., Qin, S., \& Nie, Z. (2018). Chemical fractions and availability of zinc in winter wheat soil in response to nitrogen and zinc combinations. Frontiers in plant science, 9, 1489. https://doi.org/10.3389/fpls.2018.01489.

Marschner, H. (2011). Marschner's mineral nutrition of higher plants. Academic press.

Mo, Z., Ashraf, U., Tang, Y., Li, W., Pan, S., Duan, M., ... \& Tang, X. (2018). Nitrogen application at the booting stage affects 2-acetyl-1-pyrroline, proline and total nitrogen contents in aromatic rice. Chilean journal of agricultural research, 78(2), 165-172. https://scielo.conicyt.cl/scielo.php?pid=S0718$58392018000200165 \&$ script $=$ sci arttext\&tlng $=p$

Nadaf, A. B., Wakte, K. V., \& Zanan, R. L. (2014). 2Acetyl-1-pyrroline biosynthesis: from fragrance to a rare metabolic disease. J Plant Sci Res, 1, 102-108.
RD. (2016). Rice knowledge bank. Rice Department. http://www.ricethailand.go.th/rkb3/index.htm. Accessed on 11 June 2021.

Reuter, D.J., \& Robinson, J. B. (1997). Plant Analysis an Interpretation Manual. CSIRO Publishing. Collingwood.

Roy, S., Banerjee, A., BasaK, N., Kumar, J., \& Mandal, N. P. (2020). Aromatic Rice. In The Future of Rice Demand: Quality beyond Productivity; de Oliveira, A.C., Pegoraro, C., Viana, V.E., Eds.; Springer: Cham, Switzerland, 2020; pp. 251-258. ISBN-10: 3030375102.

Singh, R. K., Singh, U. S., \& Khush, G. S. (2000). Aromatic rices Oxford and IBH Publishing Co. Pvt. Ltd., New Delhi, 1-128.

TREA. (2021). White Rice Quates. Thai Rice Exporter Association. http://www.thairiceexporters.or.th/price_eng.html

Vanavichit, A., Kamolsukyeunyong, W., Siangliw, M., Siangliw, J. L., Traprab, S., Ruengphayak, S., ... \& Tragoonrung, S. (2018). Thai Hom Mali Rice: origin and breeding for subsistence rainfed lowland rice system. Rice, 11(1), 1-12. https://thericejournal.springeropen.com/articles/1 0.1186/s12284-018-0212-7

Wolf, B. (1999). Chapter 6: Soil pH. In the Fertile Triangle: The Interrelationship of Air, Water and Nutrients in Maximizing Soil Productivity. ISBN-10: 1560228784.

Yang, S., Zou, Y., Liang, Y., Xia, B., Liu, S., Ibrahim, M., ... \& Zhu, J. (2012). Role of soil total nitrogen in aroma synthesis of traditional regional aromatic rice in China. Field Crops Research, 125, 151-160. https://doi.org/10.1016/j.fcr.2011.09.002

Yoshihashi, T., Huong, N. T. T., \& Inatomi, H. (2002). Precursors of 2-acetyl-1-pyrroline, a potent flavor compound of an aromatic rice variety. Journal of agricultural and food chemistry, 50(7), 2001-2004. https://pubs.acs.org/doi/abs/10.1021/jf011268s 